\title{
Evaluasi produktivitas alat gali muat menggunakan metode overall equipment effectiveness pada pit utara PT. Bara Prima Pratama, jobsite batu ampar
}

\author{
Adree Octova $^{1)}$, Roges Tomara Mahesa ${ }^{2 *}$ \\ ${ }^{12}$ Jurusan Teknik Pertambangan, Fakultas Teknik, Universitas Negeri Padang \\ adree@ft.unp.ac.id; rogestomaramahesa@gmail.com*
}

\begin{abstract}
ABSTRAK
PT. Bara Prima Pratama merupakan perusahaan pertambangan batubara yang terletak di Provinsi Riau. Pada kegiatan penambangannya alat gali-muat utama yang digunakan pada Pit Utara adalah dua unit Excavator Doosan DX 500 LCA HD dan satu unit Excavator Doosan DX 300 LCA HD. PT. Bara Prima Pratama Jobsite Batu Ampar menetapkan target produksi pengupasan overburden di pit utara sebesar 310.000 bcm per bulan, sedangkan realisasi produksi pengupasan overburden di pit utara pada bulan April 2021 sebesar 165.205 bcm. Dari data realisasi tersebut dapat disimpulkan bahwa produksi pengupasan overburden tidak mencapai target yang telah ditetapkan. Tujuan dari penelitian ini adalah agar target produksi pengupasan overburden dapat berjalan secara optimal dengan melakukan analisis produktivitas lebih lanjut mengenai jam kerja alat, mencari penyebab dan tindakan yang harus dilakukan untuk mencapai target serta melakukan perbaikan untuk mengoptimalkan kinerja alat gali muat. Salah satu metode yang tepat digunakan dalam mengatasi permasalahannya adalah metode Overall Equipment Effectiveness yang merupakan alat pengukuran performa proses produksi yang dapat mengukur bermacam-macam losses yang terjadi dan mengidentifikasi potensi improvement, dengan menggunakan metode ini dapat diketahui area yang perlu ditingkatkan untuk mencapai target produksi. Kemudian digunakan metode fishbone dengan mencari sebab akibat yang menyebabkan produksi pengupasan overburden tidak tercapai, kemudian dilakukan upaya perbaikan dari loss time dengan penerapan teknik $5 \mathrm{~W}+1 \mathrm{H}$. Setelah dilakukan analisis dan upaya perbaikan didapatkan total produksi pengupasan overburden sebesar 382.227,06 bcm yang berarti telah mencapai target bahkan melebihi target produksi sebesar $310.000 \mathrm{bcm}$. Akan tetapi nilai OEE masih < 85\% dari nilai OEE standar kelas dunia yaitu $\geq 85 \%$ dan masih ada ruang untuk dilakukan improvement.
\end{abstract}

Kata kunci: Produksi, Pengupasan Overburden, Excavator Doosan, Overall Equipment Effectiveness, Fishbone Methode, $5 \mathrm{~W}+1 \mathrm{H}$

\section{ABSTRACT}

PT. Bara Prima Pratama is a coal mining located in Riau Province. In its mining activities, the main digging equipment used by Pit Utara are two units of Doosan DX 500 LCA HD Excavator and one unit of Doosan DX 300 LCA HD Excavator. PT. Bara Prima Pratama Jobsite Batu Ampar has set a production target for overburden stripping in the north pit of $310,000 \mathrm{bcm}$ per month, while the realization of overburden stripping production in the north pit in April 2021 is 165,205 bcm. From the realization data, it can be concluded that the overburden stripping production did not reach the target set by the company. The purpose of this research is that the overburden stripping production target can run optimally by conducting further productivity analysis regarding the working hours of the equipment, looking for causes and actions that must be taken to achieve the target and making improvements to optimize the performance of the digging equipment. One of the appropriate methods used in overcoming these problems is the Overall Equipment Effectiveness method which is a production process performance measurement tool that can measure various losses that occur and identify potential improvements. Achieve production targets. After that, the fishbone method was used to find the cause and effect that caused the overburden stripping production to not be achieved, then an effort was made to improve the loss time by applying the $5 \mathrm{~W}+1 \mathrm{H}$ technique. After analysis and improvement efforts, the total overburden stripping production was $382,227.06 \mathrm{bcm}$, which means that it has reached the target and even exceeded the production target of $310,000 \mathrm{bcm}$. However, the OEE value is still $<85 \%$ of the world class standard OEE value which is $\geq 85 \%$ and there is still room for improvement. 
Keyword: Production, Overburden Stripping, Excavator Doosan, Overall Equipment Effectiveness, Fishbone Methode, $5 \mathrm{~W}+1 \mathrm{H}$

diunggah: November 2021, direvisi: Desember 2021, diterima: Desember 2021, dipublikasi: Desember 2021

Copyright (c) 2021 Adree Octova, Roges Tomara Mahesa

This is an open access article under the CC-BY license

\section{PENDAHULUAN}

Pertambangan dan energi merupakan industri yang strategis dan berperan penting bagi sektor pembangunan Indonesia. Salah satu potensi tambang yang dimiliki Indonesia adalah sumberdaya dan cadangan batubara. Pertambangan batubara adalah pertambangan endapan karbon yang terdapat di dalam bumi, termasuk bitumen padat, gambut, dan batuan aspal (UU No 3 Tahun 2020). PT. Bara Prima Pratama merupakan perusahaan swasta nasional yang bergerak dalam bidang pertambangan dengan unit penambangannya terletak di daerah Desa Batu Ampar, Kecamatan Kemuning, Kabupaten Indragiri Hilir, Provinsi Riau. PT. Bara Prima Pratama menerapkan sistem tambang terbuka (Open Pit) dengan bahan galian yang ditambang adalah batubara. Metode penambangan yang digunakan adalah metode Conventional Mining yang merupakan metode penambangan dengan menggunakan alat galimuat dan alat angkut. Perusahaan ini berusaha memenuhi target produksinya dengan tujuan agar mampu memenuhi permintaan domestik dan ekspor. Tercapainya target produksi dari jumlah yang telah direncanakan merupakan salah satu hal yang paling utama dalam proses kegiatan penambangan. Agar target produksi batubara tercapai maka perlu meningkatkan produksi pengupasan lapisan overburden. Dalam mencapai target produksi suatu perusahaan harus melakukan optimalisasi terhadap peralatan mekanis yang digunakan. Pada kegiatan penambangan PT. Bara Prima Pratama Jobsite Batu Ampar Pit Utara menggunakan alat galimuat utama Excavator Doosan DX 500 LCA HD, Excavator Doosan DX 300 LCA HD.

PT. Bara Prima Pratama Jobsite Batu Ampar menetapkan target produksi pengupasan overburden di pit utara sebesar $310.000 \mathrm{bcm}$ per bulan, sedangkan realisasi produksi pengupasan overburden di pit utara dengan alat gali-muat Excavator Doosan DX 500 LCA HD dan Excavator Doosan DX 300 LCA HD pada bulan April 2021 sebesar 165.205 bcm. Dari data realisasi tersebut dapat disimpulkan bahwa produksi pengupasan overburden di pit Utara pada bulan April 2021 tidak mencapai target yang telah ditetapkan oleh perusahaan. Ketidaktercapaian target produksi tersebut disebabkan oleh waktu kerja alat-alat mekanis yang tidak efektif karena adanya hambatan yang menyebabkan tingginya loss time yang terjadi pada alat gali muat, sehingga turunnya produktivitas alat gali muat yang digunakan, dan menyebabkan tidak tercapainya target produksi yang telah direncanakan.

Agar target produksi pengupasan overburden dapat berjalan secara optimal serta dapat memaksimalkan waktu kerja efektif alat gali-muat yang bekerja, untuk itu perlu dilakukan analisis produktivitas lebih lanjut mengenai jam kerja alat, mencari penyebab dan tindakan yang dilakukan untuk mencapai target serta melakukan perbaikan untuk mengoptimalkan kinerja alat gali muat. Salah satu metode yang tepat digunakan dalam mengatasi permasalahan tersebut adalah metode Overall Equipment Effectiveness (OEE) yang merupakan alat pengukuran performa proses produksi yang dapat mengukur bermacammacam losses yang terjadi dan mengidentifikasi potensi improvement.

OEE merupakan alat pengukur kinerja keseluruhan alat (complete, inclusive, whole) dalam arti peralatan dapat bekerja seperti seharusnya (Williamson, 2006). Menurut Nakajima (1988), OEE adalah metode untuk mengukur kinerja mesin atau peralatan yang digunakan di industri dengan mempertimbangkan berbagai kerugian produksi. Pengukuran ini sangat penting untuk mengetahui area mana yang perlu ditingkatkan produktivitasnya ataupun efisiensi mesin/peralatan. OEE dapat diperoleh dengan mengalikan Availability, Performance, dan Quality Rate. Sejalan dengan konsep Nakajima, OEE untuk peralatan galimuat dan angkut telah dikonfigurasikan dan didefinisikan sebagai produk dari Faktor 
Availability (Ketersediaan), Faktor Utilization (Pemanfaatan), Faktor Speed (Kecepatan) dan Faktor Bucket (Mousa dkk, 2017).

\section{METODE \\ Jenis penelitian}

Penelitian ini menggunakan jenis penelitian kuantitatif yang mengacu kepada penelitian eksperimen. Hal ini dikarenakan dalam penelitian nantinya, akan menggunakan data-data berupa angka-angka kemudian diolah dan disajikan dalam bentuk tabel atau grafi untuk mempresentasikan hasil pengolahan data tersebut kemudian dianalisis dengan menggunakan metode analisis data statistik dan persentasi. Menurut Kasiram (2008: 149) penelitian kuantitatif adalah suatu proses menemukan pengetahuan yang menggunakan data berupa angka sebagai alat menganalisis keterangan mengenai apa yang ingin diketahui.

Dalam pelaksanaan penelitian ini menggunakan data primer dan data sekunder yang kemudian dikembangkan sesuai dengan tujuan penelitian. Data primer adalah data yang diperoleh langsung pihak yang diperlukan datanya, data sekunder adalah data yang tidak diperoleh langsung dari pihak yang diperlukan datanya (Kontjojo, 2009: 34).

Berdasarkan jenis penggunaannya, penelitian ini termasuk dalam metode penelitian terapan (applied research). Penelitian terapan yaitu penelitian yang bertujuan untuk meningkatkan pengetahuan ilmiah dengan suatu tujuan praktis. Penelitian terapan berkepentingan dengan penemuan-penemuan yang berkenaan dengan aplikasi dan sesuatu konsep-konsep teoritis tertentu.

\section{Teknik pengumpulan data}

Teknik pengumpulan data yang dilakukan dalam penelitian ini adalah sebagai berikut:

\section{Studi Literatur}

Studi literatur merupakan proses kegiatan pencarian bahan pustaka terhadap masalah yang akan dibahas meliputi studi tentang analisis mengenai produksi dalam penambangan melalui berbagai percobaan, buku-buku, jurnal atau laporan studi yang sudah ada sebelumnya.

2. Pengumpulan Data

Pelaksanaan penelitian ini menggunakan beberapa cara pengumpulan informasi atau data, yang bertujuan untuk mendapatkan gambaran dan pemahaman mengenai objek yang menjadi fokus penelitian. Untuk memperoleh informasi, penulis menggunakan dua metode pengambilan data yaitu data primer dan data sekunder. Menurut Hasan (2002:82) data primer yaitu data yang dikumpulkan dengan melakukan pengamatan secara langsung di lapangan, pengamatan dilakukan dengan cara peninjauan lapangan untuk melakukan pengamatan langsung terhadap semua kegiatan di daerah yang akan diteliti sedangkan data sekunder adalah data yang diperoleh atau dikumpulkan oleh orang yang melakukan penelitian dari sumber-sumber yang telah ada (Hasan, 2002:58).

a. Data Primer

Data primer yang diperlukan dalam penelitian ini berupa data cycle time dan data loss time component alat gali-muat Excavator Doosan 500 dan Excavator Doosan 300 selama proses produksi.

b. Data Sekunder

Data sekunder yang diperlukan dalam penelitian ini berupa, data rencana produksi per bulan, data hari dan jam kerja, data spesifikasi alat gali-muat Excavator Doosan 500 dan Excavator Doosan 300, peta geologi regional, dan data stratigrafi. 


\section{Pengolahan Data}

Teknik pengolahan data yang dilakukan dalam penelitian ini yaitu dengan menggabungkan antara teori dengan data-data yang didapatkan selama kegiatan penelitian, sehingga di dapatkan pendekatan penyelesaian masalah. Proses dalam teknik pengolahaan data sangat bergantung pada data primer dan data sekunder.

a. Pengolahan Data

Data yang diperoleh diolah dengan menggunakan perhitungan menggunakan teoriteori yang telah didapatkan kemudian disajikan dalam bentuk tabel, diagram, grafik dan perhitungan penyelesaian.

b. Analisa Data

Untuk pemecahan masalah dilakukan dengan berdasarkan pada data yang diperoleh dilapangan yang didasari sumber-sumber yang berhubungan dengan masalah yang ada dilapangan.

c. Hasil dan Kesimpulan

Data yang telah diolah dan dianalisis akan menghasilkan kesimpulan berdasarkan hasil penelitian dilapangan sebagai jawaban dari rumusan masalah dan tujuan penelitian yang dilakukan.

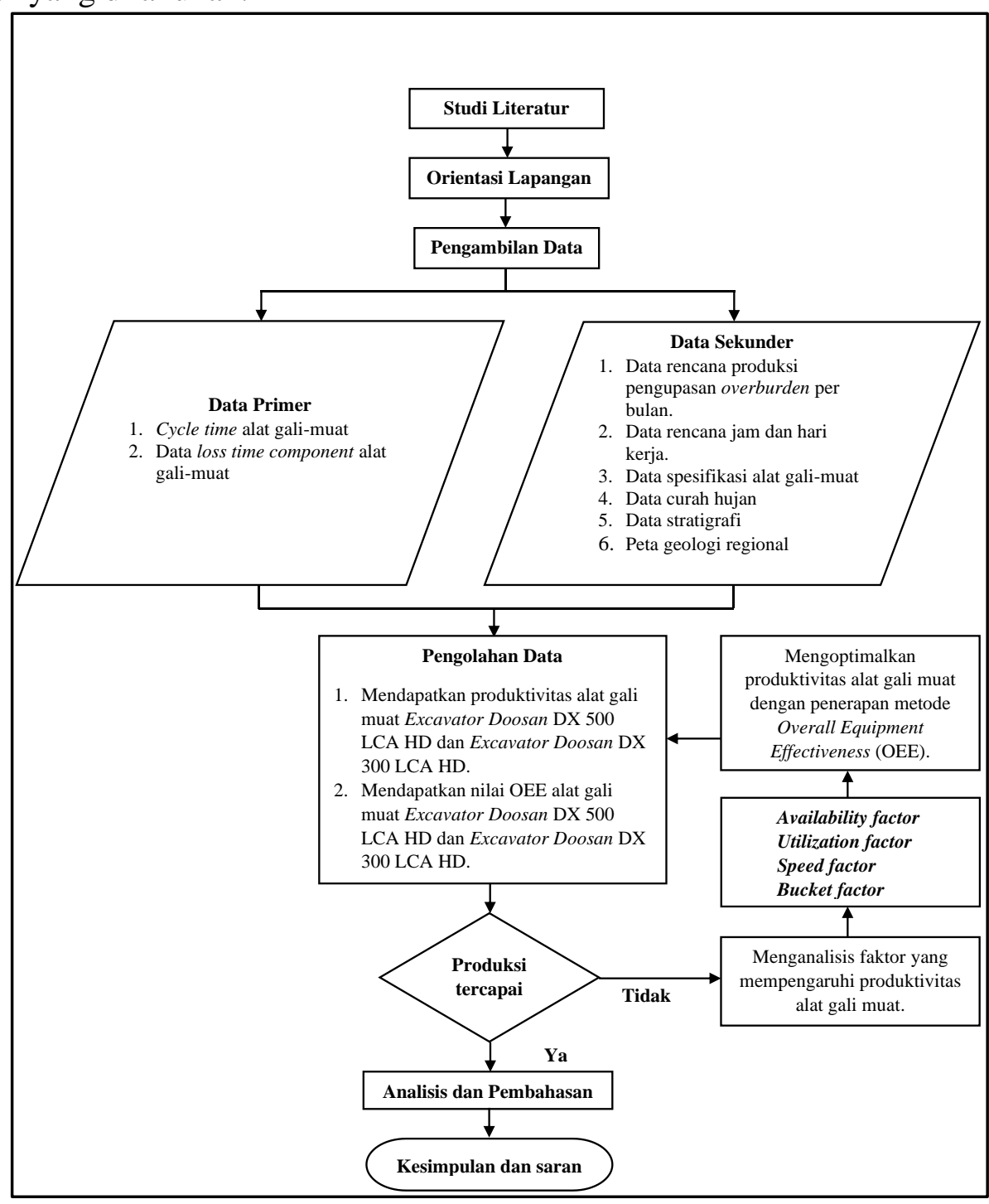

Gambar 1. Diagram alir 


\section{HASIL DAN PEMBAHASAN}

\section{Perhitungan produktivitas aktual alat gali muat}

1. Excavator Doosan DX 500 LCA HD (02)

Dikertahui:

$\begin{array}{ll}\text { Kapasitas bucket }(\mathrm{q}) & =3,28 \mathrm{~m}^{3} \\ \text { Swell faktor }(\mathrm{SF}) & =0,82 \\ \text { Fill faktor bucket }(\mathrm{k}) & =1,1 \\ \text { Effisiensi kerja }(\mathrm{E}) & =0,43 \\ \text { Cycle time }(\mathrm{CT}) & =22,46 \text { detik }\end{array}$

Penyelesaian:

$$
\begin{aligned}
& \mathrm{Q}=\frac{q \times k \times 3600 \frac{\operatorname{det} i k}{j a m} \times E}{C T} \times \mathrm{SF} \\
& \mathrm{Q}=\frac{3,28 m 3 \times 1,1 \times 3600 \times 0,43}{22,46 \text { detik }} \times 0.82 \\
& \mathrm{Q}=\mathbf{2 0 3 , 9 1} \mathrm{bcm} / \mathbf{j a m}
\end{aligned}
$$

2. Excavator Doosan DX 500 LCA HD (04)

Dikertahui:

$$
\begin{array}{ll}
\text { Kapasitas bucket }(\mathrm{q}) & =3,28 \mathrm{~m}^{3} \\
\text { Swell faktor }(\mathrm{SF}) & =0,82 \\
\text { Fill faktor bucket }(\mathrm{k}) & =1,1 \\
\text { Effisiensi kerja }(\mathrm{E}) & =0,59 \\
\text { Cycle time }(\mathrm{CT}) & =21,26 \text { detik }
\end{array}
$$

Penyelesaian:

$$
\begin{aligned}
& \mathrm{Q}=\frac{q \times k \times 3600 \frac{\operatorname{det} i k}{j a m} \times E}{C T} \times \mathrm{SF} \\
& \mathrm{Q}=\frac{3,28 m 3 \times 1,1 \times 3600 \times 0,59}{21,26 \text { detik }} \times 0.82
\end{aligned}
$$

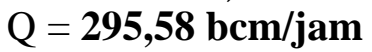

3. Excavator Doosan DX 300 LCA HD (14)

Dikertahui:

Penyelesaian:

$$
\begin{aligned}
& \text { Kapasitas bucket (q) } \quad=1,75 \mathrm{~m}^{3} \\
& \text { Swell faktor (SF) } \quad=0,82 \\
& \text { Fill faktor bucket }(\mathrm{k}) \quad=1,1 \\
& \text { Effisiensi kerja }(\mathrm{E}) \quad=0,40 \\
& \text { Cycle time }(\mathrm{CT}) \quad=19,67 \text { detik }
\end{aligned}
$$

$$
\begin{aligned}
& \mathrm{Q}=\frac{q \times k \times 3600 \frac{\text { det ik }}{\text { jam }} \times E}{C T} \times \mathrm{SF} \\
& \mathrm{Q}=\frac{1,75 \mathrm{~m} 3 \times 1,1 \times 3600 \times 0,40}{19,67 \mathrm{detik}} \times 0.82 \\
& \mathrm{Q}=\mathbf{1 1 5 , 5 6 \mathbf { ~ b c m } / \mathbf { j a m }}
\end{aligned}
$$

Hasil perhitungan produksi pengupasan Overburden dengan Excavator Doosan DX 500 LCA HD dan Excavator Doosan DX 300 LCA HD bulan April 2021 dapat dilihat pada Tabel 10 berikut ini: 
Tabel 1. Produktivitas alat gali muat

\begin{tabular}{clccc}
\hline No & \multicolumn{1}{c}{ Unit } & $\begin{array}{c}\text { Waktu Kerja Efektif } \\
(\text { jam/bulan) }\end{array}$ & $\begin{array}{c}\text { Produksi per jam } \\
\text { (bcm) }\end{array}$ & $\begin{array}{c}\text { Produksi per } \\
\text { bulan (bcm) }\end{array}$ \\
\hline 1 & $\begin{array}{l}\text { Excavator Doosan DX 500 LCA } \\
\text { HD (02) }\end{array}$ & 231,39 & 203,91 & $47.182,74$ \\
2 & $\begin{array}{l}\text { Excavator Doosan DX 500 LCA } \\
\text { HD (04) }\end{array}$ & 314,55 & 295,58 & $92.974,69$ \\
3 & $\begin{array}{l}\text { Excavator Doosan DX 300 LCA } \\
\text { HD (14) }\end{array}$ & 216,75 & 115,56 & $25.047,63$ \\
\hline Total produksi bulan April 2021 & & $\mathbf{1 6 5 . 2 0 5 , 0 6}$ \\
\hline Target produksi per bulan & & $\mathbf{3 1 0 . 0 0 0}$ \\
\hline Ketercapaian target produksi & $\mathbf{5 3 , 2 9 \%}$ \\
\hline
\end{tabular}

Berdasarkan hasil perhitungan produksi alat gali muat menunjukkan bahwa produksi pada bulan April 2021 adalah sebesar 165.205,06 bcm/bulan atau 53,29\% dari target produksi sebesar $310.000 \mathrm{bcm} / \mathrm{bulan}$. Maka dapat disimpulkan bahwa target produksi pengupasan overburden pada bulan April 2021 tidak tercapai.

Perhitungan produktivitas alat gali muat dengan metode overall equipment effectiveness (OEE)

1. Excavator Doosan DX 500 LCA HD (02)

Berikut merupakan data yang disediakan untuk perhitungan produksi dengan menggunakan metode OEE dari alat gali muat Excavator Doosan DX 500 LCA HD (02) pada bulan April 2021.

Tabel 2. Nilai parameter untuk perhitungan nilai OEE excavator doosan DX 500

LCA HD (02)

\begin{tabular}{ccccccc}
\hline TT & AT & UT & Ctp & Cta & Opc & Oac \\
\hline 720 & 529 & 231,39 & 20 & 22,46 & 3,28 & 2,91 \\
\hline
\end{tabular}

2. Excavator Doosan DX 500 LCA HD (04)

Berikut merupakan data yang disediakan untuk perhitungan produksi dengan menggunakan metode OEE dari alat gali muat Excavator Doosan DX 500 LCA HD (02) pada bulan April 2021.

Tabel 3. Nilai parameter untuk perhitungan nilai OEE excavator doosan DX 500

\begin{tabular}{ccccccc}
\multicolumn{7}{c}{ LCA HD (04) } \\
\hline TT & AT & UT & Ctp & Cta & Opc & Oac \\
\hline 720 & 529 & 314,55 & 20 & 21,26 & 3,28 & 2,91 \\
\hline
\end{tabular}

3. Excavator Doosan DX 300 LCA HD (14)

Berikut merupakan data yang disediakan untuk perhitungan produksi dengan menggunakan metode OEE dari alat gali muat Excavator Doosan DX 300 LCA HD (14) pada bulan April 2021. 
Tabel 4. Nilai parameter untuk perhitungan nilai OEE excavator doosan DX 300 LCA HD (14)

\begin{tabular}{ccccccc}
\hline TT & AT & UT & Ctp & Cta & Opc & Oac \\
\hline 720 & 529 & 216,75 & 19 & 19,67 & 1,75 & 1,51 \\
\hline
\end{tabular}

Dari nilai parameter di atas maka dapat diperoleh hasil perhitungan komponen OEE, nilai OEE dan produksi berdasarkan OEE pada Excavator Doosan DX 500 LCA HD (02), Excavator Doosan DX 500 LCA HD (04), Excavator Doosan DX 300 LCA HD (14) dapat dilihat pada tabel berikut ini:

Tabel 5. Hasil perhitungan nilai OEE excavator doosan DX 500 LCA HD (02), excavator doosan DX 500 LCA HD (04), excavator doosan DX 300 LCA HD (14)

\begin{tabular}{lccccccc}
\multicolumn{1}{c}{ Unit } & A & U & S & B & OEE & O ( $\left.\mathbf{m}^{\mathbf{3}}\right)$ & $\begin{array}{c}\text { O }\left(\mathbf{m}^{\mathbf{3}}\right) \\
(\mathbf{a k t u a l})\end{array}$ \\
\hline $\begin{array}{l}\text { Excavator Doosan DX 500 } \\
\text { LCA HD (02) }\end{array}$ & 0,73 & 0,43 & 0,89 & 0,89 & 0,25 & 106.272 & $45.696,96$ \\
$\begin{array}{l}\text { Excavator Doosan DX 500 } \\
\text { LCA HD (04) }\end{array}$ & 0,73 & 0,59 & 0,94 & 0,89 & 0,36 & $153.031,68$ & $90.288,69$ \\
$\begin{array}{l}\text { Excavator Doosan DX 300 } \\
\text { LCA HD (14) }\end{array}$ & 0,73 & 0,40 & 0,96 & 0,86 & 0,25 & $57.296,84$ & $22.918,74$ \\
\hline & & & & & & & \\
\hline
\end{tabular}

Berdasarkan hasil perhitungan nilai Overall Equipment Effectiveness (OEE) dari alat gali muat Excavator Doosan DX 500 LCA HD (02), Excavator Doosan DX 500 LCA HD (04), Excavator Doosan DX 300 LCA HD (14) pada bulan April 2021 diperoleh nilai OEE berturut-turut $0.25,0.36$, dan 0.25 ini berarti ke efektifan penggunaan peralatan secara keseluruhan berturut-turut hanya 25\%,36\%, dan $25 \%$ yang berarti kurang dari standar OEE kelas dunia yaitu 85\%. Dari hasil perhitungan dengan metode OEE juga diperoleh total hasil produksi dari alat gali muat Excavator Doosan DX 500 LCA HD (02), Excavator Doosan DX 500 LCA HD (04), Excavator Doosan DX 300 LCA HD (14) pada bulan April 2021 sebesar $158.904,39 \mathrm{bcm}$ yang mana produksi overburden tidak mencapai target produksi $310.000 \mathrm{bcm}$.

\section{Diagram fishbone}

Setelah dilakukan perhitungan produksi dari alat gali muat Excavator Doosan DX 500 LCA HD (02), Excavator Doosan DX 500 LCA HD (04), Excavator Doosan DX 300 LCA HD (14) dengan menggunakan metode Overall Equipment Effectiveness (OEE) dapat diketahui bahwa rendahnya nilai OEE disebabkan oleh adanya hambatan yang menyebabkan tingginya loss time. Akar penyebab tingginya loss time pada Alat Gali Muat Excavator Doosan DX 500 LCA HD (02), Excavator Doosan DX 500 LCA HD (04), dan Excavator Doosan DX 300 LCA HD (14) dalam bentuk diagram fishbone (diagram sebab akibat) berikut ini: 


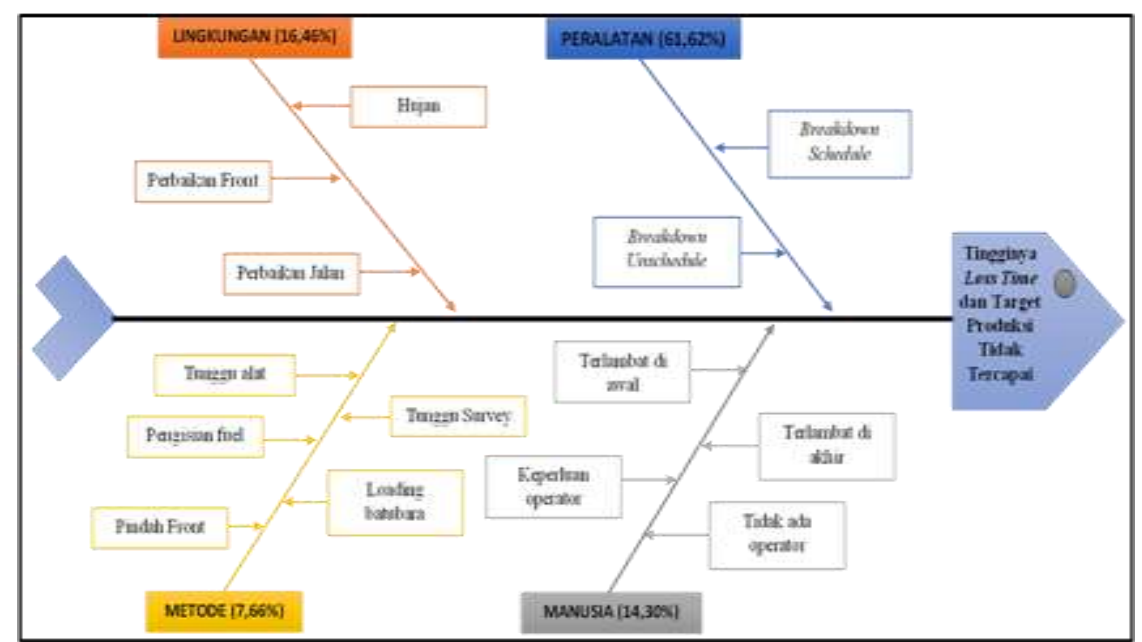

Gambar 2. Diagram fishbone penyebab loss time excavator doosan DX 500 LCA HD (02)

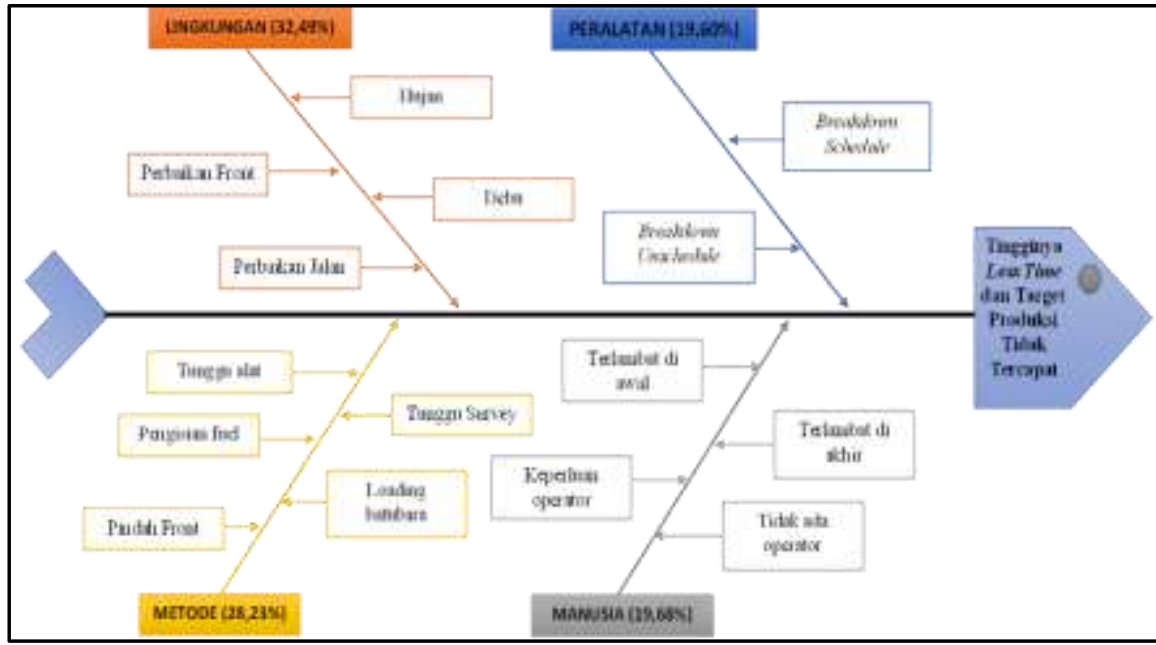

Gambar 3. Diagram fishbone penyebab loss time excavator doosan DX 500 LCA HD (04)



Gambar 4. Diagram fishbone penyebab loss time excavator doosan DX 300 LCA HD (14)

Untuk dapat mencapai nilai OEE alat gali muat yang optimal agar tercapai target produksi pengupasan overburden, maka perlu dilakukan langkah-langkah untuk meminimalisir hambatan kerja yang menyebabkan tingginya loss time yaitu dengan 
meminimalisir nilai delay time yang merupakan waktu hilang dalam jam operasi yang dapat dikendalikan. Dalam hal ini rencana perbaikan delay time dilakukan dengan penerapan teknik $5 \mathrm{~W}+1 \mathrm{H}$ kemudian digunakan metode toleransi skala terkecil dalam perbaikan nilai delay time tersebut.

Perhitungan produksi pengupasan overburden dengan metode overall equipment effectiveness (OEE) setelah perbaikan Loss Time

Setelah dilakukan perbaikan pada delay time maka diperoleh nilai Overall Equipment Effectiveness (OEE) pada Alat Gali Muat Excavator Doosan DX 500 LCA HD (02), Excavator Doosan DX 500 LCA HD (04), dan Excavator Doosan DX 300 LCA HD (14) sebagai berikut:

1. Excavator Doosan DX 500 LCA HD (02)

Berikut merupakan data yang disediakan untuk perhitungan produksi dengan menggunakan metode OEE dari alat gali muat Excavator Doosan DX 500 LCA HD (02) pada bulan April 2021 setelah perbaikan delay time.

Tabel 6. Nilai parameter untuk perhitungan nilai OEE excavator doosan DX 500

LCA HD (02) setelah perbaikan

\begin{tabular}{ccccccc}
\hline TT & AT & UT & Ctp & Cta & Opc & Oac \\
\hline 720 & 529 & 329,18 & 20 & 22,46 & 3,28 & 2,91 \\
\hline
\end{tabular}

2. Excavator Doosan DX 500 LCA HD (04)

Berikut merupakan data yang disediakan untuk perhitungan produksi dengan menggunakan metode OEE dari alat gali muat Excavator Doosan DX 500 LCA HD (04) pada bulan April 2021 setelah perbaikan delay time.

Tabel 7. Nilai parameter untuk perhitungan nilai OEE excavator doosan DX 500 LCA HD (04) setelah perbaikan

\begin{tabular}{ccccccc}
\hline TT & AT & UT & Ctp & Cta & Opc & Oac \\
\hline 720 & 529 & 433,15 & 20 & 21,26 & 3,28 & 2,91 \\
\hline
\end{tabular}

3. Excavator Doosan DX 300 LCA HD (14)

Berikut merupakan data yang disediakan untuk perhitungan produksi dengan menggunakan metode OEE dari alat gali muat Excavator Doosan DX 300 LCA HD (14) pada bulan April 2021 setelah perbaikan delay time.

Tabel 8. Nilai parameter untuk perhitungan nilai OEE excavator doosan DX 300 LCA HD (14) setelah perbaikan

\begin{tabular}{ccccccc}
\hline TT & AT & UT & Ctp & Cta & Opc & Oac \\
\hline 720 & 529 & 463,87 & 19 & 19,67 & 1,75 & 1,51 \\
\hline
\end{tabular}

Dari nilai parameter di atas maka dapat diperoleh hasil perhitungan komponen OEE, nilai OEE dan produksi berdasarkan OEE pada Excavator Doosan DX 500 LCA HD (02), 
Excavator Doosan DX 500 LCA HD (04), Excavator Doosan DX 300 LCA HD (14) setelah dilakukan perbaikan pada delay time dapat dilihat pada tabel berikut ini:

Tabel 9. Hasil perhitungan nilai OEE excavator doosan DX 500 LCA HD (02), excavator doosan DX 500 LCA HD (04), excavator doosan DX 300 LCA HD (14) setelah perbaikan.

\begin{tabular}{lccccccc}
\hline \multicolumn{1}{c}{ Unit } & A & U & S & B & OEE & O $\left(\mathbf{m}^{3}\right)$ & $\begin{array}{c}\mathbf{O}\left(\mathbf{m}^{3}\right) \\
(\mathbf{a k t u a l})\end{array}$ \\
\hline $\begin{array}{l}\text { Excavator Doosan DX 500 } \\
\text { LCA HD (02) }\end{array}$ & 0,73 & 0,62 & 0,89 & 0,89 & 0,36 & $153.539,17$ & $95.542,58$ \\
$\begin{array}{l}\text { Excavator Doosan DX 500 } \\
\text { LCA HD (04) }\end{array}$ & 0,73 & 0,82 & 0,94 & 0,89 & 0,50 & $212.836,74$ & $174.272,66$ \\
$\begin{array}{l}\text { Excavator Doosan DX 300 } \\
\text { LCA HD (14) }\end{array}$ & 0,73 & 0,88 & 0,96 & 0,86 & 0,54 & $128.195,08$ & $112.411,82$ \\
\hline & \multicolumn{7}{c}{ Total }
\end{tabular}

Berdasarkan tabel 9 di atas dari hasil perhitungan nilai Overal Equipment Effectivenes (OEE) dari alat gali muat Excavator Doosan DX 500 LCA HD (02), Excavator Doosan DX 500 LCA HD (04), Excavator Doosan DX 300 LCA HD (14) setelah dilakukan perbaikan nilai loss time didapatkan nilai OEE secara berturut-turut 0,36, 0,50, dan 0,54 atau sebesar 36\%, 50\% dan 54\% yang berarti bahwa nilai OEE meningkat dari sebelum dilakukannya perbaikan terhadap nilai delay time, akan tetapi nilai tersebut masih masih kurang dari standar nilai OEE kelas dunia yaitu $85 \%$, hal tersebut menandakan masih bisa dilakukan perbaikan terhadap nilai OEE alat gali muat.

Kemudian berdasarkan hasil perhitungan produksi menggunakan metode OEE dengan nilai OEE setelah dilakukan perbaikan terhadap delay time didapatkan produksi pengupasan overburden dari alat gali muat Excavator Doosan DX 500 LCA HD (02), Excavator Doosan DX 500 LCA HD (04), Excavator Doosan DX 300 LCA HD (14) secara keseluruhan sebesar 382.227,06 bcm yang berarti telah mencapai target bahkan melebihi target produksi pengupasan overburden sebesar $310.000 \mathrm{bcm}$.

\section{SIMPULAN} berikut:

Berdasarkan penelitian yang telah dilakukan, maka dapat ditarik kesimpulan sebagai

1. Produktivitas aktual alat gali muat Excavator Doosan DX 500 LCA HD (02), Excavator Doosan DX 500 LCA HD (04), Excavator Doosan DX 300 LCA HD (14) pada bulan April 2021 165.205,06 bcm dari target produksi yang telah direncanakan yaitu $\mathbf{3 1 0 . 0 0 0}$ bcm.

2. Berdasarkan hasil perhitungan dengan metode Overall Equipment Effectiveness diperoleh nilai OEE alat gali muat Excavator Doosan DX 500 LCA HD (02), Excavator Doosan DX 500 LCA HD (04), Excavator Doosan DX 300 LCA HD (14) pada bulan April 2021 sangat rendah yaitu secara berturut-turut sebesar $25 \%, 36 \%$, dan $25 \%$ dengan total hasil produksinya sebesar $\mathbf{1 5 8 . 9 1 8 , 7 4} \mathrm{bcm}$.

3. Dari hasil analisis dengan menggunakan metode diagram fishbone didapatkan akar penyebab faktor hambatan yang menyebabkan tingginya loss time pada alat gali muat Excavator Doosan DX 500 LCA HD (02), Excavator Doosan DX 500 LCA HD (04), Excavator Doosan DX 300 LCA HD (14) pada bulan April yaitu faktor peralatan, faktor lingkungan, faktor manusia dan faktor metode. Untuk mengoptimalkan kinerja alat gali 
muat yang bekerja dilakukan perbaikan pada nilai loss time yaitu nilai delay time (waktu hilang yang bisa dikendalikan). Upaya perbaikan dilakukan dengan menerapkan metode $5 \mathrm{~W}+1 \mathrm{H}$, setelah dilakukan upaya perbaikan dilakukan pengurangan nilai delay time dengan toleransi standar terkecil yang pernah terjadi selama bulan April 2021.

4. Hasil perhitungan produksi dengan penerapan metode Overal Equipment Effectiveness (OEE) setelah dilakukan upaya perbaikan dengan pengurangan nilai delay time sesuai toleransi standar terkecil yang pernah terjadi pada alat gali muat Excavator Doosan DX 500 LCA HD (02), Excavator Doosan DX 500 LCA HD (04), Excavator Doosan DX 300 LCA HD (14) didapatkan total produksi pengupasan overburden sebesar $\mathbf{3 8 2 . 2 2 7 , 0 6} \mathrm{bcm}$ yang berarti telah mencapai target bahkan melebihi target produksi sebesar $\mathbf{3 1 0 . 0 0 0} \mathrm{bcm}$ dengan nilai OEE alat gali muat secara berturut-turut sebesar 36\%, 50\% dan 54\% yang berarti terjadi peningkatan, akan tetapi nilai OEE tersebut masih tergolong rendah dari nilai OEE standar kelas dunia yaitu $\geq 85 \%$ dan masih ada ruang untuk dilakukan improvement.

\section{DAFTAR PUSTAKA}

Agustino, Y., \& Gusman, M. 2018. Evaluasi Optimalisasi Alat Gali Muat dengan Metoda Overall Equipment Effectiveness (OEE) untuk Memenuhi Target Produksi Batubara Bulan Maret 2018 di Pit 1 Utara Bangko Barat PT. Bukit Asam Tbk, Tanjung Enim Sumatera Selatan. Bina Tambang, 3(4), 1409-1422.

Akande, J., Lawal, A. I., \& Aladejare, A. E. 2013. Optimization of the overall equipment efficiency (OEE) of loaders and rigid frame trucks in NAMDEB Southern Coastal Mine Stripping fleet, Namibia. Earth Science, 2(6), 158-166.

Anggraini, R. 2020. Optimalisasi Produktivitas Batu Andesit Menggunakan Metode Quality Control Circle Untuk Memenuhi Target Produksi Batu Andesit 18.000 ton/bulan Pada PT Pebana Adi Sarana Nagari Manggilang Kee. Pangkalan Koto Baru Kah. Lima Puluh Kota, Provinsi Sumatera Barat. (Doctoral dissertation, Universitas Negeri Padang).

Elevli, S., \& Elevli, B. 2010. Performance Measurement Of Mining Equipments By Utilizing OEE. Acta Montanistica Slovaca, 15(2), 95.

Fauziah, N. 2009. Aplikasi fishbone analysis dalam meningkatkan kualitas produksi teh pada PT Rumpun Sari Kemuning, kabupaten Karanganyar.

Fiscalaga, D. A., Maryanto, M., \& Munir, S. 2019. Optimalisasi Fleet Management dalam Produksi Hauling Batubara di PT Muara Alam Sejahtera Kecamatan Merapi Barat, Kabupaten Lahat, Provinsi Sumatera Selatan.

Hadiyat, M. I. S., Budiasih, E., \& Atmaji, F. T. D. 2019. Analisis Tingkat Efektivitas Mesin Cutting Pada Pabrik Pipa Menggunakan Metode Overall Equipment Effectiveness $(O E E)$ Dengan Penerapan Total Productive Maintenance (TPM). eProceedings of Engineering, 6(2).

Hastary, S., Yusuf, A. A., \& Awaludin, R. 2021. Optimalisasi Proses Produksi Dengan Menggunakan Metode Overall Equipment Effectiveness. Jurnal Bina Bangsa Ekonomika (JBBE), 14(1). 
Kasiram, M. 2010. Metodologi Penelitian: Kualitatif-kuantitatif.

Kuntjojo. 2009. Metode penelitian. Kendiri: tidak diterbitkan

Mohammadi, M., Rai, P., \& Gupta, S. 2017. Performance evaluation of bucket based excavating, loading and transport (BELT) equipment-an OEE approach. Archives of Mining Sciences, 62.

Murnawan, H. 2014. Perencanaan Produktivitas Kerja Dari Hasil Evaluasi Produktivitas Dengan Metode Fishbone di Perusahaan Percetakan Kemasan Pt. X’. Heuristic, 11(01).

Nuryono, A. 2018. Analisis Efektifitas Kinerja Excavator Pada Aktifitas Ob Removal Penambangan Batubaramenggunakan Metode Oee (Studi Kasus: Pt. Rml EmbalutKalimantan Timur). Journal of Industrial Manufacturing, 3(2), 79-88.

Partanto, Projosumarto. 1995. Pemindahan Tanah Mekanis. Bandung: Jurusan Teknik Pertambangan ITB.

Specifications \& Application Handbook Komatsu Edition 30, 2009

Sumarya. 2014. Peralatan Tambang. Padang: Fakultas Teknik Universitas Negeri Padang.

Tague. 2005. The Quality Toolbox. United States of America: ASQ

Tenriajeng, A. T. 2003. Pemindahan Tanah Mekanis. Jakarta: Penerbit Gunadarma.

Triwardani, D. H., Rahman, A., \& Mada Tantrika, C. F. 2013. Analisis overall equipment effectiveness (OEE) dalam meminimalisi six big losses pada mesin produksi dual filters DD07 (studi kasus: PT. Filtrona Indonesia, Surabaya, Jawa Timur). Jurnal Rekayasa dan Manajemen Sistem Industri, 1(2), p379-391.

Undang-Undang Nomor 4 Tahun 2009 Tentang Pertambangan Mineral Dan Batubara

Vijayakumar, S. R., \& Gajendran, S. 2014. Improvement of overall equipment effectiveness (OEE) in injection moulding process industry. IOSR J Mech Civil Eng, 2(10), 4760.

Waqas, M., Tariq, S. M., Shahzad, M., Ali, Z., \& Saqib, S. 2015. Performance Measurement Of Surface Mining Equipment By Using Overall Equipment Effectiveness. Pakistan Journal of Science, 67(2).

Williamson, R. M. 2006. Using overall equipment effectiveness: the metric and the measures. Strategic Work System, Inc, 1-6.

Yanto, Indonesianto. 2014. Pemindahan Tanah Mekanis. Tenik Pertambangan, UPN Veteran: Yogyakarta. 